\title{
La sociología económica y fiscal de los impuestos: perspectivas y hallazgos para Chile
}

\author{
Jorge Atria \\ Universidad Diego Portales, Chile
}

\begin{abstract}
RESUMEN: Este artículo analiza la tributación desde una perspectiva de sociología económica y fiscal. Se argumenta que del mismo modo como la sociología ha explicado la racionalidad de los agentes, la naturaleza de las transacciones económicas y el funcionamiento de los mercados examinando los fundamentos sociales, culturales y políticos de la economía, una línea específica de investigación permite hacer lo propio con los impuestos. Para esto, en base a una extensa revisión de literatura, se expone la perspectiva de la sociología económica y fiscal en tres temas centrales: las instituciones impositivas, el consentimiento y el cumplimiento tributario. En cada caso se discute cómo tales visiones complementan o desafían la mirada de la economía tributaria. Más ampliamente, se reflexiona sobre cómo estas miradas no solo pueden aportar a una comprensión más precisa de los impuestos en la vida real, sino también a conseguir sistemas tributarios más justos,
\end{abstract}

\footnotetext{
Jorge Atria es Profesor de la Escuela de Sociología, Universidad Diego Portales, Chile, e Investigador Asociado del Centro de Estudios de Conflicto y Cohesión Social (COES), Chile. Sociólogo y Magíster en Sociología de la Pontificia Universidad Católica de Chile, Doctor en Sociología de la Freie Universität Berlin, Alemania. Sus intereses de investigación son la sociología económica y fiscal, la estratificación social y la sociología de la cultura. En 2021 coeditó el libro Impuestos justos para el Chile que viene: diagnósticos y desafíos tributarios para un nuevo pacto fiscal (Fondo de Cultura Económica). Dirección: Av. Ejército 333, piso 3, Santiago Centro, Santiago, Chile, CP 8370127 . Email: jorge.atria@mail.udp.cl.

Este artículo se elaboró en el marco del Proyecto Fondecyt № 11181223, financiado por ANID (Agencia Nacional de Investigación y Desarrollo, Chile). Agradezco el apoyo del Centro de Estudios de Conflicto y Cohesión Social (ANID/FONDAP № 15130009) y también de Carlos Budnevich por su apoyo en la elaboración de los gráficos de este artículo. Asimismo, al equipo editorial y a los pares revisores, cuyos comentarios y sugerencias mejoraron significativamente el artículo.
} 
que permitan enfrentar los enormes desafíos socioeconómicos que exhiben las sociedades contemporáneas.

PalABRAS Clave: tributación, Estado, redistribución, sociología económica, sociología fiscal, Chile

RECIBIDO: mayo 2021 / ACEPTADO: noviembre 2021

\title{
The Economic and Fiscal Sociology of Taxes: Perspectives and Findings for Chile
}

\begin{abstract}
This article analyzes taxation from an economic and fiscal sociology perspective. It is argued that, just as sociology has explained the rationality of agents, the nature of economic transactions and the functioning of markets by examining the social, cultural and political foundations of the economy, a specific line of research allows to do the same with focus on taxes. For this purpose, based on an extensive literature review, the perspectives of economic and fiscal sociology are presented in three main issues: tax institutions, consent and tax compliance. In each case, I discuss how such views complement or challenge the views of tax economics. More broadly, it reflects on how these perspectives can contribute not only to a more accurate understanding of taxation in real life, but also to building fairer tax systems that allow to face the huge socioeconomic challenges of contemporary societies.
\end{abstract}

KEYWORDS: taxation, State, redistribution, economic sociology, fiscal sociology, Chile

ReCeived: May 2021 / Accepted: November 2021

a sociología económica ha ganado terreno en las últimas décadas

como área de estudio que aporta nuevas perspectivas y explicaciones para comprender el ámbito económico, la creación de los mercados y la racionalidad de los actores al interactuar en ellos. Partiendo de la afirmación de que la economía está inmersa en la sociedad, y por ende conectada con el resto de las instituciones sociales y políticas en contextos históricos específicos, como también de la constatación de racionalidades múltiples que conducen a acciones económicas con distintas orientaciones o fines, se han mostrado con gran claridad los fundamentos sociales, culturales y políticos de la economía, y con ello, las múltiples maneras en que los valores e intereses permean su funcionamiento en la vida cotidiana.

Uno de los temas en que esto se ha desarrollado recientemente es en los impuestos. Aunque la tributación formó parte importante de las 
preocupaciones de las ciencias sociales clásicas, su estudio se fue especializando cada vez más dentro de la economía y el derecho. En especial, desde la economía se consideró como un asunto particularmente técnico que debía ser analizado exclusivamente a partir de modelos matemáticos abstractos que descansan en los supuestos de racionalidad de los actores para diseñar el sistema tributario, incluyendo las tasas impositivas óptimas y el diseño de incentivos para el cumplimiento.

En las últimas décadas, sin embargo, estas premisas han sido largamente desafiadas. En línea con el desarrollo de la sociología económica, y compartiendo varias de sus premisas fundamentales, se ha formado una nutrida línea de investigación centrada en los impuestos como forma de expandir el análisis sobre el Estado y también como punto de observación para examinar otros temas que atingen a las sociedades actuales, como la relación entre ciudadanos y entre ciudadanía y Estado, la aplicación concreta de visiones de justicia distributiva y la cultura política de un país. Entendida como un área de estudio, la sociología fiscal no solo establece un diálogo fructífero con la sociología económica, sino también con la larga tradición de estudios sobre fiscalidad, que contempla desde el análisis del origen del Estado moderno y las burocracias hasta el foco en capacidad fiscal como estrategia comparativa entre países.

Este artículo se enmarca en las perspectivas de sociología económica y fiscal para examinar la tributación, en tanto fenómeno social de gran densidad analítica y que ha ganado relevancia en la discusión política y académica internacional. Para esto se recurre a la creciente literatura que estudia los impuestos desde esta aproximación con dos propósitos. Primero, examinar cómo los supuestos de la sociología económica se aplican en este campo, planteando con ello la necesidad de reconocer los fundamentos sociales de los sistemas tributarios que les otorgan una forma específica en cada país. Esto se hará abordando tres temas centrales: las instituciones, el consentimiento y el cumplimiento. Segundo, se discuten esos contenidos con foco en la realidad chilena. Esto permite poner los rasgos centrales de su política tributaria en perspectiva, teniendo en consideración la incipiente literatura que ha abordado a Chile en específico.

El resto del artículo se organiza de la siguiente manera: en la sección que sigue se introducen los supuestos básicos de la sociología económica y de la sociología fiscal. A continuación, desde este marco analítico se 
argumenta cómo la comprensión puramente económica de los impuestos tiene limitaciones que restringen la exploración de sus fenómenos en los tres ámbitos ya mencionados -instituciones, consentimiento y cumplimiento-, problematizando la evaluación de sus instituciones y el riesgo de diseñar políticas equívocas que no necesariamente aumenten el cumplimiento tributario. Luego se presenta la política tributaria chilena en general y los tres temas que han sido presentados en el marco analítico en particular, con el propósito de reflexionar sobre cómo se comprenden estos rasgos en base a la evidencia ya existente para Chile. Finalmente se concluye.

\section{Sociología económica y sociología fiscal: premisas y conceptos}

\section{Las bases de la sociología económica}

La sociología económica ha sido definida como la aplicación de marcos de referencia, variables y modelos explicativos de la sociología al conjunto de actividades relacionadas con la producción, la distribución, la intercambio y consumo de bienes y los servicios escasos (Smelser y Swedberg 2005 , 3). El aporte fundamental de la sociología para la comprensión de la vida económica se refleja en sus perspectivas sobre la interacción personal y grupal, las estructuras sociales - las instituciones-, los mecanismos de control social —sanciones, normas y valores_-, las redes sociales, el género, los contextos culturales y la dimensión internacional de la vida económica (Smelser y Swedberg 2005, 3). Varios autores resaltan también la introducción del poder en el fortalecimiento de estas perspectivas (Fligstein 1996; Beckert 1996; Dobbin 2005).

El punto de partida de la sociología económica se encuentra en el escepticismo ante dos supuestos de la economía neoclásica: primero, la idea de que los mercados y los intercambios legalmente regulados comprenden lo principal de la actividad económica real. Segundo, la concepción de que el autointerés sin constricciones constituye la única motivación, o al menos la primaria, de la acción económica (Portes 2010, 13). Ambos supuestos se inscriben en una visión de la economía separada de la sociedad, tanto para explicar el origen y evolución de las instituciones como también las decisiones cotidianas que comprenden las transacciones económicas y la operación de los mercados (Swedberg y Granovetter 
1992). En la concepción de los actores, por su parte, prevalece la visión de un homo economicus, fundamentalmente maximizador de la utilidad y que sigue un comportamiento asumido como perfectamente racional, lo que hace posible predecir los resultados de sus acciones ( $\mathrm{Ng}$ y Tseng 2008).

Las aproximaciones diferenciadas que la economía y la sociología fueron desarrollando con el avance del siglo XX no se corresponden con las formulaciones de diversos autores en el inicio de ambas disciplinas, cuando los contornos de ambas no eran claros. Sin embargo, la perspectiva asociada a Pareto ${ }^{1}-\mathrm{y}$ refrendada posteriormente por Paul Samuelson y otros autores - de separar las dos disciplinas a partir de la premisa de que la economía se ocupa del comportamiento racional y la sociología del comportamiento irracional, se terminó imponiendo, marcando la trayectoria predominantemente paralela de ambas ciencias (Swedberg 1990).

La sociología económica prolifera inicialmente como una respuesta a los supuestos de la ciencia económica enfatizando tres orientaciones: (i) las transacciones económicas no ocurren aisladas ni en un vacío, sino que están incrustadas en entramados de sociabilidad y sistemas culturales; (ii) los medios racionales dirigidos hacia fines específicos suelen terminar generando consecuencias diferentes e incluso opuestas a aquellas originalmente pensadas; y (iii) la economía en ningún caso puede ser visualizada como una cancha pareja, enfatizando el rol del poder (Portes $2010,13)$. En términos generales, diversos autores que siguen estas perspectivas no problematizan que el análisis económico esté centrado en los mercados o en los intercambios, sino en que no se comprendan tales fenómenos como procesos sociales que están mediados política, simbólica e interaccionalmente.

Aunque estas tres orientaciones adquieren una forma sistematizada y estilizada en la sociología económica -más precisamente en la 'Nueva Sociología Económica', como se denominó a este grupo en la última década del siglo XX-, su historia es más extensa y tiene raíces anteriores. A modo de ejemplo, Max Weber (2008 [1922]) en su teoría de la acción advierte que la ciencia económica soslaya las motivaciones no económicas de las personas, que no se asocian con la satisfacción

\footnotetext{
${ }^{1}$ Aunque dicha asociación Pareto ha sido discutida por la literatura. Ver Aspers (2001).
} 
de necesidades materiales y que influyen en sus acciones. Igualmente, los actores - sociales, pues siempre están en relación con otros y tienen en consideración el comportamiento de otros - no tienen información económica completa en cada situación, no siempre seleccionan los medios más adecuados para un fin ni tampoco están siempre orientados a la consecución de bienes económicos (Weber 2008 [1922]). Desde esta aproximación, Weber propuso cuatro tipos distintos de acción, entre los cuales solo uno de ellos es la acción racional con arreglo a fines individuales — cercano al modelo de acción neoclásica—, pese a que aun así no deja de ser una acción social económica. La acción económica, en ese sentido, se pone en juego en nuestras relaciones sociales y no se puede predecir solo a partir de las preferencias individuales, dado que constantemente estamos negociando nuestras preferencias en interacción con otros (Zelizer 2010).

Otro ejemplo es el análisis de la incrustación o inmersión (embeddedness) de la economía de Karl Polanyi. Para Polanyi (1992 [1957]), la economía humana está entrelazada en instituciones económicas y no económicas, considerando a las segundas tan vitales como las primeras, otorgando de esta forma a la religión o al gobierno tanta importancia para la estructura y operación de la economía como a las instituciones monetarias o a la disponibilidad de equipamiento para desempeñar algunas actividades laborales (Polanyi 1992, 34).

Así, la inmersión de la economía en la sociedad no solo refleja la institucionalización del proceso económico en sí, a partir de la interdependencia entre distintos componentes que dan funcionamiento a la economía; también permite afirmar que todo intercambio económico hace posible la integración de lo social y lo económico, favoreciendo la estabilidad (Polanyi 1992). Es esto lo que Polanyi critica a la pretensión de los mercados entendidos como entidades autorreguladas que descansan en commodities ficticios (el trabajo, el dinero y la tierra); tal dislocación de lo social produciría las condiciones deshumanizantes que él atestiguaba en su época (Beckert 2009, 43). De esta forma, la incrustación de la economía implica atender las precondiciones sociales y políticas para la realización de las funciones económicas y también las consecuencias que puede tener un proceso de desincrustación, es decir, la expansión de mercados cuya pretensión autorregulable implica un desacople del resto de las instituciones. Por cierto, una consecuencia de la incrustación de la 
economía llevaría a Polanyi a argumentar que procesos de desincrustación conducirían a procesos de reincrustación como respuesta del resto de las instituciones —en especial en la forma de intervención políticapara volver a vincular la economía con la sociedad (Beckert 2009, 49).

\section{Las bases de la sociología fiscal}

Paralelamente a la Nueva Sociología Económica, comenzaban a surgir trabajos orientados a la revitalización de la literatura sobre el Estado con foco en los impuestos y las finanzas públicas. El punto de partida de estas preocupaciones, sin embargo, no es este, sino que remite a autores clásicos de la economía y sociología, como Rudolf Goldscheid (1917), quien proponía una 'sociología de las finanzas' para profundizar en la posición del Estado en la sociedad. Este foco contemplaba una integración mayor entre el Estado como ente jurídico y su función presupuestaria, y llamaba a otorgar a la recaudación y gasto, como al análisis histórico de los impuestos y créditos estatales, un renovado valor para la investigación social.

Un año después, Schumpeter (2000 [1918]) refrendaba estos argumentos planteando que la historia fiscal de un pueblo es una parte central de su historia general, al influenciar su trayectoria y la forma en que enfrenta sus conflictos. Para Schumpeter (2000, 150), la clave analítica de la historia fiscal no se agota en una comprensión mayor de la economía, sino que tiene también rendimiento para escudriñar la cultura, estructura social y bases políticas de las sociedades, conectando con investigaciones de otras áreas que resaltan que los impuestos reflejan los valores y límites críticos de distintas épocas, concretándose en diseños técnicos y configuraciones regulatorias (Schultz 1992; Sahm 2019).

Volviendo a las últimas décadas del siglo $\mathrm{XX}$, la revitalización de la sociología fiscal no solo invitaba a releer a los clásicos, a pensar el carácter situado e inmerso de los impuestos y a estudiar la formación de políticas fiscales a partir de las interacciones sociales y los contextos históricos e institucionales, en línea con la nueva sociología económica. También invitaba a entender los impuestos como un ángulo necesario para profundizar en la comprensión del estado (Campbell 1993). Esta motivación conecta la Nueva Sociología Fiscal con las investigaciones que abordaban al Estado en la segunda mitad del siglo XX. La combinación de estos enfoques refuerza la idea de que la obtención de recursos 
por medio de la tributación es una condición central de la existencia fiscal junto al monopolio de la violencia y el ejercicio de autoridad política sobre un territorio (e.g. Skocpol y Amenta 1986; Martin, Mehrotra y Prasad 2009), que tuvo un rol en el fortalecimiento de un régimen administrativo burocrático (e.g. Weber 2008, 727), en el financiamiento de guerras, y en términos generales en la formación de los Estados modernos (e.g. Mann 1984; Tilly 1975; Scheve y Stasavage 2016).

En un libro del año 2009, que representa una compilación seminal de estudios de Nueva Sociología Fiscal (Martin, Mehrotra y Prasad 2009), se sugieren tres grandes contribuciones analíticas a las líneas precedentes: primero, el foco preponderante en instituciones sociales informales, en respuesta a trabajos de economía y ciencia política centrados en instituciones como las constituciones y las leyes. Esta orientación lleva a profundizar empíricamente en la incrustación de los impuestos en relaciones sociales que "no por no estar escritas están menos institucionalizadas" (Martin, Mehrotra y Prasad 2009, 13). Este interés descansa en el supuesto de que los sistemas tributarios están formados por configuraciones particulares de confianza, clivajes sociales y los variados roles que cumplen en cada sociedad la familia, el trabajo o la religión. A su vez, los sistemas tributarios inciden también en las formas que adquieren tales configuraciones e instituciones.

Segundo, la Nueva Sociología Fiscal otorga centralidad al contexto histórico, nutriéndose del enfoque de trayectorias dependientes (pathdependence) para sostener que el desarrollo de las instituciones sociales está determinado por coyunturas críticas, continuidades institucionales y trayectorias históricas divergentes y contingentes (Martin, Mehrotra y Prasad 2009, 13). Este énfasis es una respuesta a las teorías de la modernización y a las aproximaciones que sugieren trayectorias de progreso continuo que no están sujetas a contingencias transformadoras, planteamiento que refutan las múltiples formas que han adquirido los sistemas tributarios a nivel global (e.g. Atria, Groll y Valdés 2018; Kato y Toyofuku 2018; Steinmo 1993).

Tercero, la Nueva Sociología Fiscal sería diferenciadora por su interés en fenómenos tributarios cuyo análisis se da a un nivel social más que individual. Aquí no se considera únicamente el foco tradicional en guerras o mercados laborales, sino también en desigualdades o género, todos los cuales contribuirían a continuar la exploración en torno al rol de los 
impuestos en el surgimiento de la democracia, el desarrollo estatal y la solidaridad social (Martin, Mehrotra y Prasad 2009, 14).

Teniendo en consideración tanto los trabajos clásicos como los de la Nueva Sociología Fiscal, y siguiendo a Atria (2015, 217-218), las agendas de investigación interesadas en una perspectiva sociológica de la fiscalidad pueden beneficiarse del foco y de los desarrollos teóricos de este campo en la medida en que persigan los siguientes objetivos:

1. Explorar el desarrollo de los Estados, las ideas sobre fiscalidad y los determinantes de la capacidad fiscal. Aunque la capacidad fiscal no solo descansa en la política tributaria (Lieberman 2009), analizar su evolución histórica con énfasis en los contextos históricos permite acceder a fuentes clave de información sobre las diferencias en la formación del Estado entre países, considerando el rol que se les otorga, las ideas que lo justifican y cómo ellas se relacionan con discusiones como el crecimiento económico, el bienestar social y las arquitecturas de solidaridad institucional.

2. Ensanchar la observación del Estado, al complementar el estudio del gasto social con el del financiamiento del aparato público, los instrumentos tributarios para incentivar o desincentivar acciones o servicios, o el grado de cumplimiento de las obligaciones tributarias. Estos enfoques plantean la importancia de estudiar tanto 'cómo se gasta', como también 'cómo se recauda' (Campbell 1993).

3. Plantear desde otro ángulo las interrogantes sobre producción y reproducción de la desigualdad. La centralidad de la función tributaria en la obtención de recursos fiscales favorece el análisis sobre la capacidad de reducir grandes diferencias de ingreso y la disposición de las elites políticas a favorecer tal esfuerzo, a través del estudio de la continuidad de mecanismos impositivos injustos o de las negociaciones durante reformas tributarias (Fairfield 2015).

4. Indagar en la legitimidad fiscal. Al constituir una relación permanente entre ciudadano y fisco, el pago de impuestos y las percepciones acerca de estos informan sobre las experiencias de los ciudadanos frente al Estado que implícitamente han ayudado a construir (Lipsky 2010), cómo identifican su pertenencia a una comunidad política y el rol que le asignan al Estado como ente que los representa y hace posible varios aspectos del bienestar colectivo (Grimson y Roig 2011). 
5. Examinar los acuerdos y desacuerdos en lo que atinge a dilemas distributivos y representaciones sociales del individuo y el bien común. En una economía capitalista los impuestos no son solo un método de pago para los servicios públicos, sino también el instrumento más importante con el cual el sistema político aplica una concepción de justicia distributiva (Murphy y Nagel 2002).

\section{Desacuerdos y complementos con la economía de los impuestos}

La sociología económica y la sociología fiscal pueden complementar o desafiar los análisis de la economía tributaria en una variedad de temas. Esto no debe ser percibido como una disputa disciplinaria, sino más bien, como reconocen o llevan a la práctica varios economistas contemporáneos, como un esfuerzo conjunto desde todas las ciencias sociales por buscar nuevas respuestas a los grandes problemas de nuestra época que se relacionan con la economía y los impuestos, como por ejemplo las altas desigualdades, la incapacidad de la democracia para representar equitativamente las preferencias ciudadanas, la escasa movilidad ascendente hacia la jerarquía social y las fallas de la meritocracia (Shiller 2019; Atkinson 2015; Piketty 2017). Esto lleva también a que las perspectivas de sociología económica y fiscal de hecho consideren evidencia producida desde distintas disciplinas, incluyendo la propia economía. A continuación se exponen los aprendizajes y contribuciones de estas perspectivas en tres campos de interés tributario: las instituciones, el consentimiento y el cumplimiento.

\section{Instituciones}

Aunque distintas disciplinas coinciden en que las instituciones tienen un rol central para entender la economía, la definición de institución, como también las explicaciones sobre su emergencia y cambio, suelen ser diferentes. El nuevo institucionalismo económico ha adaptado la economía neoclásica partiendo del argumento de que los formalismos matemáticos no permiten una comprensión adecuada de los comportamientos económicos reales, lo cual se debe corregir estudiándolos en el marco de las restricciones que imponen las instituciones reales (Nee 2005). Con 
esta aproximación, North $(1991,97)$ define las instituciones como "restricciones humanamente concebidas que estructuran las instituciones políticas, económicas y sociales".

Sin embargo, esto no siempre adquiere más especificidad que la identificación de elementos externos que constriñen el comportamiento de los actores (Portes 2010). Asimismo, la emergencia y el cambio institucional suelen seguir una perspectiva que considera preponderantemente las fuerzas económicas -el ingreso, el capital humano y la desigualdad-como los determinantes principales, soslayando la interacción entre las instituciones y los valores, creencias e intereses en la formación de comportamientos en distintos contextos (Currie et al. 2016, 200). En ese sentido, prepondera el análisis institucional para entender cómo se forman las estructuras de incentivos (para esto se observan en especial los derechos de propiedad), cómo se reducen los costos de transacción y cómo se especifican las reglas para la competencia en los mercados, sin profundizar mayormente en cómo se vinculan las instituciones formales e informales para orientar el comportamiento de los actores ni cómo inciden en ello las normas y creencias (Nee 2005).

La aproximación sociológica a las instituciones aborda estos déficits, otorgando importancia a la historia y considerando la incrustación de las instituciones en redes complejas con otras instituciones no económicas y con la cultura para comprender su coevolución y sus consecuencias impredecibles en el comportamiento (Portes 2010; Currie et al. 2016). La sociología también remite a la incrustación para reivindicar que los actores no siguen las reglas ni ciega ni atomizadamente, como crítica a la visión subsocializada de la economía (Granovetter 1985). Se argumenta que las relaciones sociales concretas - las redes sociales para Granovetterconstituyen un punto de observación crucial para entender la información, la confianza y las motivaciones de los actores, teniendo mayor incidencia que los arreglos institucionales y las autoridades organizacionales para determinar comportamientos deshonestos. La mayor importancia concedida a los actores, sus intereses e ideas permite también considerar la capacidad de agencia para eventualmente modificar las reglas, pero también para resignificarlas o eludirlas, entre otras acciones posibles, como ha sido planteado por diversos autores en torno a las nociones de emprendimiento institucional y hermenéutica institucional (Garud, Hardy y Maguire 2007; Blyth 2002; DiMaggio 1988). 
Adicionalmente, el poder también importa en la formación de comportamiento económico, lo que se aprecia directamente en las relaciones asimétricas entre pequeñas y grandes empresas, e indirectamente en la injerencia de un conglomerado económico en la elaboración de una ley para adecuarla a su conveniencia (Dobbin 2005, 27), que es otra forma de decir que en el campo económico los actores dominantes "definen las regularidades y a veces las reglas del juego [...] modificando el entorno completo de las otras firmas y el sistema de restricciones que recae sobre ellas o el espacio de posibilidades que se les ofrece" (Bourdieu 2005, 76).

Las instituciones tributarias ilustran nítidamente estas visiones. Primero, un elemento central tiene que ver con la enorme diversidad que exhiben los sistemas tributarios en todo el mundo, tanto comparando entre países de altos ingresos como entre estos y el resto del mundo. Por ejemplo, contra las afirmaciones que supondrían la convergencia entre sistemas tributarios de acuerdo con el desarrollo económico y político, existen diferencias importantes en la tributación entre países con las democracias más antiguas y aquellos con procesos de democratización más recientes, descartando alguna explicación generalizada sobre la relación entre democracia y desarrollo tributario (Kato y Toyofuku 2018).

Estas distintas trayectorias de formación y cambio institucional sugieren que no basta con una visión subsocializada — centrada únicamente en las instituciones impositivas-, sino que se precisa analizar las interacciones entre Estado y ciudadanos para entender los fundamentos y efectividad de cada sistema tributario y el grado de cumplimiento de sus contribuyentes. Es decir, no se puede examinar la capacidad fiscal sin atender al consentimiento de los contribuyentes (Steinmo 2018).

Segundo, la formación y cambio de las instituciones tributarias tiene fuerte relación con la cultura y con coyunturas históricas específicas. Steinmo (2003) adopta esta aproximación argumentando en favor de la interdependencia en lugar de la separación entre intereses (autointerés material) e ideas (sobre política tributaria), añadiendo también las creencias (interpretaciones) y valores (preferencias normativas básicas). La evolución de la política tributaria, así, se entendería como un proceso dinámico e interactivo a partir del cual se institucionalizan ideas de política exitosas, que a su vez ayudarán a formar las creencias de los actores, lo que se entiende como 'policy feedbacks' (e.g. Campbell 2011). 
En el siglo $X X$, esto se verifica en el tránsito desde una visión en que los impuestos eran utilizados como un instrumento de política social con una función de redistribución esencial - a mediados de siglo- a una en que los impuestos no se perciben útiles para ese propósito - a fines del mismo siglo (Steinmo 2003, 228). Para Steinmo, en las reformas tributarias que cada país emprende inciden las realidades económicas específicas, pero sobre todo, más que un desplazamiento entre izquierda y derecha, lo que denotan las reformas es la transformación de ideas sobre política económica e impositiva. Esto se refleja en la creciente convicción entre diseñadores de política de que los mercados atravesarán los límites políticos sin importar el buen diseño de las políticas, en la medida en que descreen en el manejo económico con impuestos, pues se cree que reducirían la eficiencia en una economía capitalista (Steinmo 2003, 228).

Esta mirada aplica también a la administración tributaria. Incluso en aquellas que logran altos niveles de recaudación, como en Suecia, la alta legitimidad y confianza institucional se pone en juego cotidianamente en las relaciones con los contribuyentes, siendo parte de sus tareas la búsqueda constante de nuevas estrategias para reproducir los vínculos de esa forma (Björklund Larsen 2017). Inversamente, administraciones tributarias que deben lidiar con bajo cumplimiento tributario deben adoptar una variedad de estrategias de fiscalización. Estas contemplan desde una aproximación legalista a una acomodadiza, que en lugar de privilegiar la legislación considera un acercamiento amigable y empático por parte de los fiscalizadores (Wynter y Oats 2021). Estudiando el caso de Jamaica, Wynter y Oats (2021) analizan la fiscalización como una tarea que involucra innovadoras prácticas en el mundo real y en un contexto donde no siempre se cuenta con las estructuras organizacionales adecuadas para cumplir con las metas oficiales. Estas prácticas no siempre siguen la lógica tributaria e implican una alta capacidad de adaptación con respuestas flexibles que no siempre son racionales ni objetivas (Wynter y Oats 2021, 287). Esta aproximación resalta que cuando el foco y los incentivos están puestos exclusivamente en aumentar la recaudación en lugar del cumplimiento y la moral tributaria, se puede derivar a mayor corrupción y hostigamiento de contribuyentes honestos, erosionando la justicia tributaria (Wynter y Oats 2021, 287-288). 


\section{Consentimiento}

Los estudios de sociología económica y fiscal sobre los impuestos han dedicado bastante atención a los fundamentos que explican la disposición o indisposición de las personas a pagar impuestos. Estas indagaciones responden al diagnóstico de que la ciencia económica tiende a asumir como dadas las respuestas de los actores a preguntas no económicas sobre legitimidad y autoridad política, derechos individuales y poder del Estado (Graetz y Wilde 1985, 357). Esto no tiene que ver únicamente con el incumplimiento tributario (lo que se revisa en la subsección siguiente), sino también con el cumplimiento: las personas pueden pagar los impuestos que se le piden pero aun así resistirlos y movilizarse directa o indirectamente contra ellos para cambiarlos - 'capitulative compliance' para McBarnet (2001) —, cuestión que a lo largo de la historia se ha documentado repetidamente, apareciendo los impuestos como un determinante central de protestas y revoluciones (e.g. Murphy 2016).

Las bases del consentimiento no solo preocupan a los estudios impositivos, sino también a aquellos asociados con la legitimidad del Estado. En el ámbito tributario, el consentimiento refleja una relación más amplia entre ciudadanía y Estado, lo que Abelin (2012) entiende como un 'lazo fiscal' que involucra dinámicas específicas de reconocimiento intersubejtivo. Tal aproximación concibe al Estado esencialmente como una entidad política y no económica; una entidad soberana a la cual la ciudadanía contribuye para regenerar a la comunidad y con ello para elevar su propia condición moral (Abelin 2012). Consiguientemente, el consentimiento pone en juego cómo el Estado es percibido y cómo la ciudadanía comprende la cooperación social (Grimson y Roig 2011). En este sentido, el pago de impuestos representa simbólicamente la renovación de la membresía a una comunidad política, por parte del contribuyente, y un desafío para ofrecer una imagen de credibilidad y autoridad trascendental, por parte del fisco.

En sociedades antiguas, el consentimiento impositivo solía cristalizarse en sistemas tributarios con altos niveles de discrecionalidad, donde los contribuyentes tenían muy poco espacio para incidir en las decisiones e impuestos utilizados, mientras en la actualidad prevalece un esquema contractual, donde el intercambio de impuestos por servicios es más explícito (Moore 2008). Este esquema, con numerosas variaciones en cada sociedad, tiene en común su conformación a partir de procesos 
de negociación entre ciudadanos y el Estado, redundando en la expansión de la representatividad, receptividad y efectividad gubernamental por medio de mayor participación en las decisiones colectivas, mayor transparencia y acceso a bienes públicos (Bräutigam 2008; Moore 2008). Por cierto, las variaciones de este esquema permiten imaginar Estados con distintos niveles de representatividad, receptividad y efectividad, como también disímiles disposiciones de los contribuyentes a pagar impuestos.

En estos enfoques no es posible entender los comportamientos de los contribuyentes puramente desde el autointerés. Tampoco se visualizan sociedades donde existen solo disposiciones positivas por parte de sus contribuyentes, pagando impuestos únicamente por una cuestión de principios (Levi 1988). Comprender las múltiples combinaciones entre estos polos es responder a la pregunta de cómo se debe combinar consentimiento con coacción, considerando los intereses de ambos lados: capacidad fiscal de ofrecer credibilidad y provisión competente de servicios y habilidad para convencer a la ciudadanía de que su contribución es condición de posibilidad para lograr dichos propósitos (Levi 1988).

En la actualidad, autores como Sloterdijk (2010) observan negativamente la capacidad fiscal de proyectar esa imagen y proponen incluso transformar el paradigma tributario para entender los impuestos como donaciones en lugar de como obligaciones; tal transformación haría posible superar la noción de contribuyentes como deudores, fortaleciendo la democracia. Otros autores disienten, sea planteando que muchos ciudadanos sí tienen disposición a pagar impuestos porque lo entienden como una responsabilidad cívica y una obligación moral (e.g. Williamson 2017), sea recordando que el pago de impuestos no puede comprenderse como un perjuicio a la propiedad, sino como un requisito para protegerla. Esto, dado que la propiedad privada es una convención legal definida en parte por el propio sistema tributario, razón por la cual no tiene existencia ni validez independiente, lo que debe llevar a entender los impuestos como parte del sistema de derechos de propiedad que ellos mismos ayudan a establecer (Murphy y Nagel 2002, 8). ${ }^{2}$

\footnotetext{
2 "Todos nacimos en un sistema legal detalladamente estructurado que regula la adquisición, el intercambio y la transmisión de derechos de propiedad, y la propiedad viene a parecer la cosa más natural del mundo. Pero la economía moderna en la que ganamos nuestros salarios, nos hacemos dueños de nuestras casas, cuentas bancarias, ahorros de pensiones $\mathrm{y}$ otras posesiones personales y en la cual usamos nuestros recursos para consu-
} 
Un último aspecto resaltado por aproximaciones no económicas a la tributación tiene que ver con la importancia que tiene para los contribuyentes el comportamiento de los otros. La percepción sobre si el sistema es justo y todos pagan lo que deberían es crucial para informar la decisión propia (Sá, Martins y Gomes 2014; Bergman 2009; Levi 1988). Esto es importante porque mientras más se considere que uno es el único que paga los impuestos que corresponden, existirá una evaluación más negativa del sistema y una mayor pérdida de consentimiento (Grimson y Roig 2011). Asimismo, la sensación de que uno es 'el único que juega limpio', en términos más amplios, revela la percepción de que existen diferencias intolerables de comportamiento en relación con las reglas y variaciones inaceptables en el trato que las instituciones otorgan a los individuos, incrementando la desconfianza social y la pérdida de civismo (Rosanvallon 2012, 333-334).

Un ejemplo que ilustra la importancia del consentimiento es la comparación que Lieberman (2001) establece entre la política tributaria brasileña y sudafricana para estudiar por qué la segunda fue mucho más exitosa que la primera para recaudar el impuesto al ingreso ${ }^{3}$ en el siglo XX. Lieberman argumenta que existen divergencias en torno a la definición de Comunidad Política Nacional, en particular en las maneras de abordar los clivajes étnicos y espaciales en ambas constituciones a fines del siglo XIX e inicios del siglo XX. Para el autor, el foco de tales coyunturas críticas incidió decisivamente en la configuración de sus políticas tributarias.

Para analizar este efecto consideró, primero, que para el impuesto al ingreso todos los gobiernos dependen en mayor medida de los individuos más ricos, quienes tienen más recursos para pagar ese impuesto, lo que justificaba concentrarse en las actitudes de las elites brasileña y sudafricana ante este tributo. Segundo, era importante determinar si la Comunidad Política Nacional se definía en términos incluyentes o excluyen-

mir o invertir, sería imposible sin el marco que proporciona el gobierno con el sustento de los impuestos. Esto no quiere decir que los impuestos están más allá de una evaluación — solo que el foco de esta tiene que ser el sistema de derechos de propiedad que ellos hacen posible. No podemos empezar por asumir como dada, sin necesidad de justificación ni tampoco sujeta a evaluación crítica, la distribución inicial de posesiones - lo que pertenece a las personas originalmente, lo que es de ellas previo a la interferencia del gobierno" (Murphy y Nagel 2002, 8; traducción propia).

${ }^{3}$ En Chile, este impuesto se conoce como 'impuesto a la renta'. Por este motivo, en este artículo se alterna entre ambas nociones para referir al mismo tributo. 
tes. Mientras más excluyente, mayor cohesión social intragrupal, pero no entre grupos. Los individuos tienen mayor disposición a pagar si confían en que el grupo con que se identifican -'nosotros' - se beneficiará de la acción fiscal en lugar de que los recursos se transfieran a 'los otros.' Esta última percepción llevaría a una evaluación negativa del Estado. En cambio, definiciones inclusivas que reconocen distintos grupos dentro de la comunidad política, crean fragmentación de clases, favoreciendo que los grupos de altos ingresos perciban intereses compartidos con otros.

Sus resultados muestran que la Constitución sudafricana de 1909 afirmaba la supremacía blanca, mientras que en la brasileña de 1891 no se establecieron distinciones relacionadas con origen o color de la piel. Esto produjo distintas condiciones para la cohesión interclase e intraclase: en Brasil, las identidades regionales de las elites adquieren mayor relevancia, lo que se tradujo en una menor disposición a la solidaridad entre clases. En Sudáfrica, en cambio, tal solidaridad sí era posible en la medida en que la comunidad blanca mostraba empatía entre sus miembros con el propósito de consolidar sus intereses, atravesando por ende las distinciones de clase y propiciando una estructura tributaria progresiva. En Brasil, aunque la piel blanca o el origen europeo podía generar beneficios sistemáticos sobre el resto de la población, su movilización fue más inefectiva que en Sudáfrica, en un contexto de relaciones de clase fragmentadas. El consentimiento tributario se revela, de esta forma, sustentado en el sentido de pertenencia a una nación común, lo que en Sudáfrica excluía a las personas de piel negra.

\section{Cumplimiento}

La recaudación impositiva de un gobierno difiere de aquella que espera obtener según la 'letra y espíritu' de su legislación. La distancia que separa a la primera de la segunda se denomina 'brecha tributaria' y agrupa todas las razones que explican que un contribuyente incumpla su compromiso fiscal (Jorratt 2013): subdeclaración involuntaria, evasión — subdeclaración ilegal y voluntaria-y elusión —uso abusivo de la ley, sin atender la intención del legislador de reducir la carga tributaria.

Para calcular la brecha tributaria no se requiere distinguir mayormente entre evasión y elusión, ni profundizar en las motivaciones de los actores, en el sentido otorgado al incumplimiento, y en las creencias 
que sustentan dichos actos. El análisis económico permite dimensionar la pérdida total de recursos en perjuicio del fisco, pero en muchos casos asume a los individuos como agentes pasivos que reaccionan a variables exógenas, dispuestos a tributar solo en cuanto teman a las fiscalizaciones y sanciones de la autoridad (Kirchler, Maciejovsky y Schneider 2003, 536). Uno de los trabajos seminales en este tipo de análisis es el de Allingham y Sandmo (1972), quienes reciben la influencia de autores como Arrow y Becker (e.g. Becker 1968). Aunque posteriormente se han añadido nuevos factores a este modelo, aumentando su capacidad explicativa y realismo, se mantiene un enfoque que descansa mayormente en los incentivos financieros que subyacen a la decisión de evadir, así como en la afirmación de que los individuos pagan impuestos únicamente debido al temor de ser detectados y sancionados (Alm y Torgler 2011).

La sociología económica y fiscal ha desafiado esta aproximación argumentando que los contribuyentes tienen motivaciones tributarias distintas y que su disposición al pago tiene en consideración el comportamiento de los otros. Además del consentimiento, como se expuso en la subsección precedente, una forma de dar soporte a este argumento es la evidencia de que sanciones más altas y el uso de estrategias de amenaza y coerción no necesariamente disminuyen la evasión de impuestos, pudiendo incluso reducir la moral tributaria (Frey y Holler 1998; Taylor 2003), debido a que pueden desmotivar y desincentivar a las personas que tienen una disposición positiva hacia el pago de impuestos con base en actitudes cívicas y de interés por la cooperación social.

Un segundo argumento que apoya esta afirmación es que los niveles de cumplimiento son típicamente mayores que los que se podrían esperar dado el nivel de fiscalización, sugiriendo la influencia de las normas sociales sobre el comportamiento de los contribuyentes (Cummings et al. 2009). La pregunta en esta literatura es por qué tanta gente paga en lugar de evadir, dado que típicamente la probabilidad de fiscalización no es tan alta. Estos trabajos plantean también que contextos de alta confianza tendrían incidencia positiva en el cumplimiento tributario (Kogler et al. 2013).

Tales contextos pueden variar en el tiempo. Como analizan Ide y Steinmo (2009) en el caso japonés, es posible observar el tránsito desde una política tributaria sustentada en un pacto fiscal equilibrado entre trabajadores y empresas - con estas cumpliendo una función clave en 
las políticas de bienestar a cambio de paz social y promoción de la economía - a un escenario de aumento crítico de la deuda pública no explicado tanto por incrementos del gasto público, sino por la reducción de los ingresos fiscales. Esta transformación tendría origen en una creciente desconfianza en la clase política y en la burocracia, cuyo origen remite a cambios tributarios regresivos que beneficiaron a empresas y a grupos de altos ingresos en detrimento del resto de la población, en el contexto de la crisis de la burbuja inmobiliaria y financiera que afectó a Japón en la década de 1990. Esos cambios tributarios redujeron los ingresos fiscales, aumentaron la desconfianza e incrementaron la desigualdad en un país cuya cultura igualitaria resaltaba entre los países ricos. Para Ide y Steinmo (2009), este caso sugiere que cuando las políticas benefician específicamente a los grupos de altos ingresos, se erosiona el contrato social básico que sostiene los sistemas tributarios modernos, disminuyendo la disposición a pagar impuestos.

Doreen McBarnet $(2001,6)$ propone una tipología para sistematizar las distintas motivaciones de los contribuyentes hacia los impuestos, proponiendo cuatro tipos de comportamientos: (i) cumplimiento comprometido, que agrupa a quienes efectúan el pago voluntariamente; (ii) cumplimiento 'capitulativo', que define la obediencia involuntaria del pago, es decir, su realización aunque se disiente de ella; (iii) incumplimiento, caracterizado por el rechazo de la obligación tributaria; y (iv) cumplimiento creativo, que representa el trabajo sobre la forma legal de las actividades para etiquetarlas o reetiquetarlas, acomodando la ley para hacerla menos inconveniente o directamente conveniente para los fines individuales.

Que este tipo de cumplimiento sea perfectamente legal, pero al mismo tiempo anule el efecto esperado de la ley, lleva a McBarnet (2001) a entenderlo como una acción de 'evasión legal'. Para un enfoque sociológico de los impuestos, esta descripción es de interés porque permite comprender en su especificidad un problema central en la tributación contemporánea: la elusión. Caracterizar adecuadamente la elusión es fundamental porque, siguiendo la interpretación de McBarnet (2001), demuestra que las motivaciones individuales pueden llevar a distintos tipos de cumplimiento, siendo en especial el de tipo creativo - asociado a la elusión - una acción que no es automática, sino asociada a un 'trabajo legal activo' que involucra la construcción de argumentos y formas lega- 
les alternativas. Si bien este trabajo requiere la ayuda de especialistas, implica también una intencionalidad específica de los contribuyentes de querer reducir su carga utilizando estrategias particulares que no se deducen automáticamente de la ley. Esto permite dimensionar la importancia de una comprensión cabal de las motivaciones de los contribuyentes para distinguir cómo estas se cristalizan en distintos repertorios de intencionalidades y acciones.

\section{El caso chileno}

La economía ha aportado abundante evidencia para entender la política impositiva chilena. Estudios desde esta disciplina enseñan, entre otros factores, la regresividad del sistema tributario, la persistencia de este rasgo a lo largo de distintos períodos (Agostini e Islas 2018) y el predominio de los objetivos del crecimiento, eficiencia, ahorro y reinversión en la mayoría de las reformas significativas de las últimas décadas, en especial durante la dictadura (Cheyre 1986; Palma y Marcel 1990). Con foco en estructura tributaria y redistribución, se ha analizado la regresividad del IVA y la progresividad del impuesto a la renta, como también el costo que tiene la regresividad para los más pobres y el complemento que puede ofrecer el gasto social progresivo (Engel et al. 1999; Agostini 2013; López y Figueroa 2011). Asimismo, otros trabajos han estudiado el efecto de regímenes especiales ( $y$, en general, del gasto tributario) en la pérdida de recaudación, la creación de inequidades horizontales y la elusión, así como el tratamiento diferenciado de las rentas del trabajo y el capital, las bajas tasas efectivas que pagan los grupos de altos ingresos y los riesgos de las utilidades retenidas en las empresas en términos de evasión y elusión (Agostini et al. 2018; Jorratt 2013; Jorratt 2009; Fairfield y Jorratt 2016; Agostini, Martínez y Flores 2012).

¿Cómo puede contribuir una agenda de investigación sobre sociología económica y fiscal de los impuestos en Chile? Siguiendo los ejes de las instituciones, el consentimiento y el cumplimiento, es posible observar algunos hallazgos ya disponibles.

En términos institucionales, una línea creciente de estudios permite entender la formación histórica del pacto fiscal chileno, las ideas e intereses que han prevalecido en distintas épocas y también la influencia ejercida por la elite económica y política para imponer sus preferencias 
(Fairfield 2015; Napoli y Navia 2012; Atria 2014). Estos estudios enseñan que el sistema tributario no ha seguido una trayectoria lineal; distintas coyunturas históricas han generado cambios impositivos -en particular, la incertidumbre de los mercados internacionales de recursos naturales, los grandes terremotos y cambios en la institucionalidad política, en especial antes, durante y después de la dictadura-, incluyendo la introducción de impuestos progresivos, alzas de la tasa marginal máxima del impuesto a la renta y propuestas de mayores ingresos permanentes para financiar gasto social (Gil y Atria 2021; Biehl y Labarca 2018; Boylan 1996).

Pese a lo anterior, a menudo los intereses de las elites han prevalecido, configurando un pacto fiscal que aunque ha subido su recaudación, mantiene su regresividad. Pero además se trata de un pacto fiscal invisible: está basado primeramente en el IVA, un impuesto escondido que afecta el consumo y donde la mayoría no paga el impuesto a la renta. Aunque esto último puede explicarse por el bajo nivel de ingresos de la mayoría de la población, es problemático en términos de que el impuesto a la renta es visible, requiere consentimiento y confianza para ser pagado y genera inclusión política, en la medida en que hace a los ciudadanos conscientes de su condición de contribuyentes, y con ello más conscientes de sus derechos como miembros de una comunidad de iguales (Biehl, Labarca y Vela 2019).

Por su parte, la administración tributaria representa uno de los entes fiscales cuya modernización ha sido más elogiada, contando con funcionarios altamente calificados y con mecanismos avanzados de fiscalización. Sin embargo, no está ajena a los conflictos de intereses y a las preferencias de las elites en un contexto de alta desigualdad, lo que ha generado resultados dispares y tensiones internas en distintos momentos de su historia (Wormald y Cárdenas 2014; Fairfield 2015).

Estos análisis ayudan a recordar que las instituciones no solo producen incentivos y reglas para el comportamiento económico, sino también relaciones particulares entre ciudadanos y Estado, lo cual incide en la legitimidad fiscal (Atria, Groll y Valdés 2018).

Lo anterior se vincula con el consentimiento para pagar impuestos y con las percepciones sobre el Estado. Desde el lado de la ciudadanía, las encuestas de opinión pública sugieren que el anhelo de un rol más activo del Estado para reducir la desigualdad y financiar políticas sociales coexiste con cierta desconfianza hacia sus funciones y formas de gasto. 
El rol más activo del Estado se aprecia en varias encuestas: entre 1990 y 2012, datos de la Encuesta Mundial de Valores exhiben un aumento drástico de la preferencia por mayor igualdad, pasando de un $26 \%$ en 1990 a $60 \%$ en 2012. Asimismo, datos de la encuesta ISSP 2016 muestran que $70 \%$ de los encuestados respondía 'sí, sin ninguna duda' que era responsabilidad del Estado reducir las diferencias entre ricos y pobres, similar al casi 74\% que en la encuesta CEP 2019 señalaba estar 'de acuerdo' o 'muy de acuerdo' con esa afirmación. También es posible observar cómo esta mayor conciencia de las desigualdades y el anhelo por un rol más activo del Estado se han acompañado por una creciente demanda por redistribución y derechos sociales. Esto ha servido al menos en parte como fundamento de diversas propuestas de reforma tributaria, revitalizando una discusión que había estado largamente ausente en las décadas anteriores (Atria 2015, 2018).

Respecto de la desconfianza hacia las funciones y gastos del Estado, la Encuesta Adimark Bicentenario 2014 muestra, por ejemplo, que en un eje de 1 a 10, donde 1 señala la afirmación 'El Estado tiende a despilfarrar los impuestos' y 10 'El Estado gasta correctamente los impuestos', 56\% de los encuestados se ubica entre 1 y 4 , mientras $17 \%$ lo hace entre 7 y 10. La misma encuesta retrata, en todo caso, que existen bajos niveles de conciencia tributaria: es así como $28 \%$ de los chilenos declara no pagar ningún impuesto y $34 \%$ no recordaba ningún impuesto que pagara al momento de responder la encuesta, lo que resalta los problemas de un pacto fiscal invisible e indica que los ciudadanos probablemente se reconocen más como consumidores que como contribuyentes, pese a su significativa contribución a través del IVA y de otros impuestos.

Los datos de estas encuestas no sugieren una disposición de la mayoría de los ciudadanos a pagar más impuestos. No obstante, esto también podría relacionarse con la carga tributaria actual, que se apoya proporcionalmente con más dureza en los grupos bajos y medios que en los más altos, al punto de que las tasas efectivas de estos últimos son muy similares a las de los más pobres (Fairfield y Jorratt 2016; Castelletti 2013). Esto puede explicar las cifras que consistentemente exhiben distintas encuestas en favor de mayores impuestos para los grupos superiores. Contrariamente, los grupos de altos ingresos no se muestran proclives a mayores impuestos. Aunque estos expresan una gran preocupación por los más pobres, esta se plantea con el propósito de combatir fundamentalmente la pobre- 
za y no la desigualdad. El foco central de este propósito apunta a políticas educacionales y de emprendimiento que permitan el aprovechamiento de oportunidades desde una mirada que cree que, pese a las desigualdades, quienes tienen mérito pueden ascender socialmente, lo que se acompaña de una alta desconfianza en el Estado (Atria et al. 2020).

Datos recientes de la Encuesta Nacional sobre Cultura Tributaria en Chile 2021 complementan estos datos: mientras el 63,1\% está 'en desacuerdo' o 'muy en desacuerdo' con que hay justicia en la distribución de la carga tributaria, 83,5\% considera que el sistema beneficia a los más ricos, como muestran los gráficos 1 y 2 .

Gráfico 1. PERCEPCIONES DE JUSTICIA EN EL SISTEMA TRIBUTARIO CHILENO

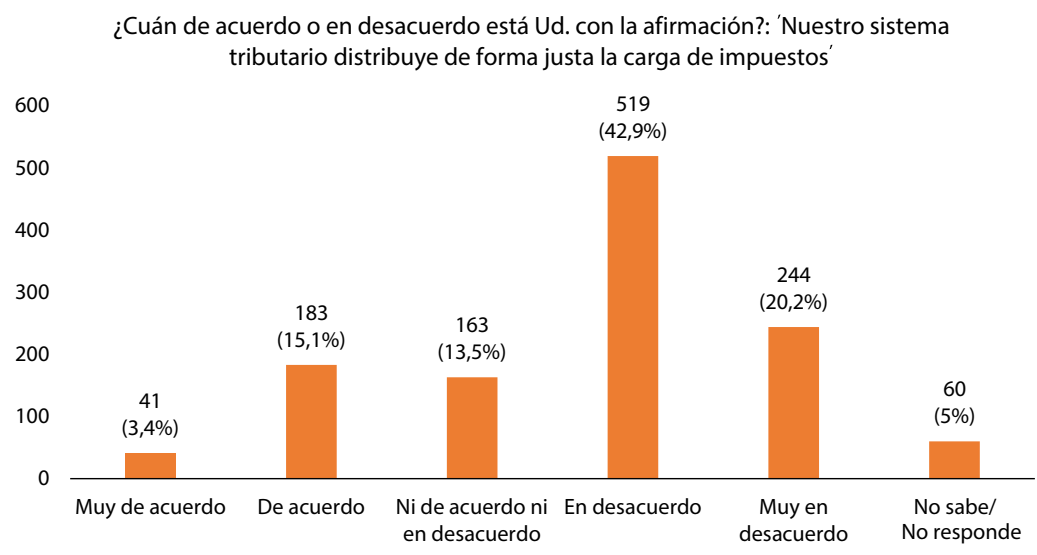

Fuente: Elaboración propia.

Por último, un estudio reciente señala que las preferencias por mayores impuestos y por progresividad tributaria no necesariamente se corresponde con la posición socioeconómica de las personas, aunque sí con sus preferencias políticas (Castillo y Olivos 2014). Es decir, no necesariamente prima el autointerés en las preferencias tributarias, pudiendo personas de distintos grupos — no necesariamente los más pobres- estar a favor de impuestos más altos y progresivos.

Las informaciones precedentes entregan elementos relevantes para indagar en el cumplimiento de las personas. Aunque pocos estudios se han centrado en este aspecto, es interesante notar que en Chile ha prevalecido una evaluación más bien positiva sobre el comportamiento 
impositivo. Esto no solo se deja ver en encuestas de opinión pública nacionales, sino también en estudios extranjeros, que ubicaban a Chile hasta hace no mucho entre las naciones más cumplidoras del mundo en el ámbito tributario, lo que se explicaría por un amplio apego al Estado de derecho (Bergman 2009). Aunque las cifras de evasión que existían en ese momento eran más positivas que las actuales —al menos en el pago del IVA (Jorratt 2013)—, esas interpretaciones no recogen adecuadamente al menos tres elementos: primero, la disposición a la elusión, que lleva a que las personas evalúen negativamente la evasión, pero a que estén dispuestas al mismo tiempo a emprender sofisticadas operaciones de planificación con el fin de reducir su carga tributaria, en especial quienes tienen los recursos para esto. Los datos sobre desplazamientos de recursos chilenos al extranjero a través de distintas modalidades dan cuenta de que este fenómeno no es irrelevante (Atria 2018).

Gráfico 2. BENEFICIADOS Y PERJUDICADOS CON LA INJUSTICIA DEL SISTEMA TRIBUTARIO CHILENO

¿Cuán de acuerdo o en desacuerdo está Ud. con la afirmación?: 'El sistema tributario actual beneficia a los más ricos y es injusto con los trabajadores comunes y corrientes'

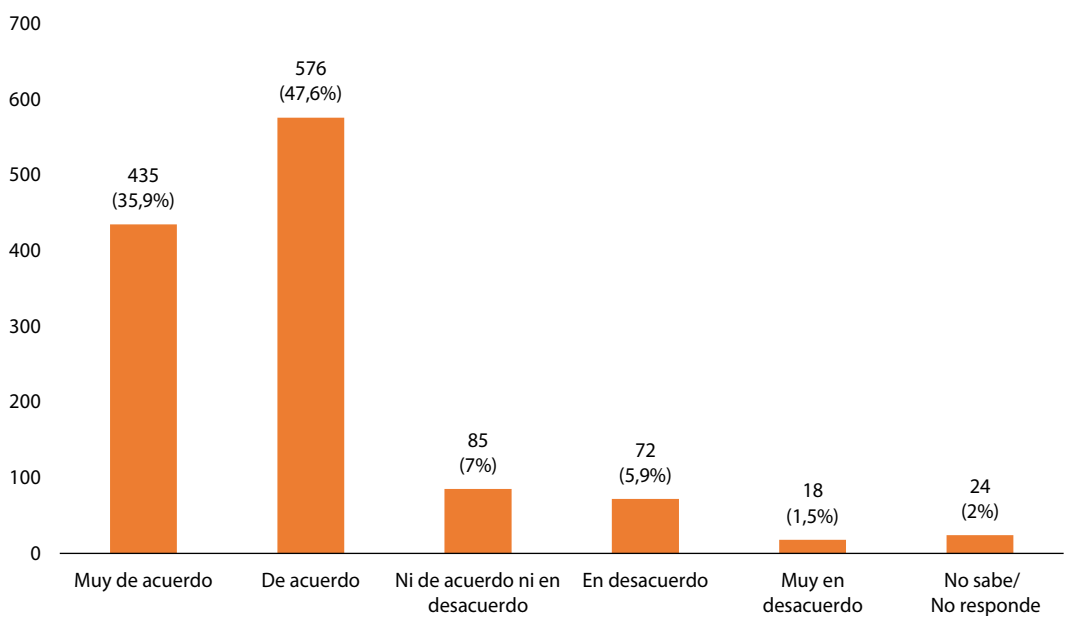

Fuente: Elaboración propia.

Segundo, el apego al Estado de derecho, reflejado en el legalismo atribuido a los chilenos, no informa sobre las distintas intencionalidades en torno al pago de impuestos. Un estudio cualitativo con miembros de la elite económica muestra que bajo el legalismo existe una amplia diver- 
sidad de disposiciones hacia la elusión, mientras en algunos prevalece el rechazo a planificaciones agresivas, en otros casos existen comportamientos más activos en torno a la reducción de la carga tributaria. Esto es fundamentado a través de cuatro repertorios de justificaciones: (i) cívico-ontológicas, es decir, debilidades formativas o culturales de ciertas personas o grupos; (ii) regulatorias, que refieren a las oportunidades que ofrece el sistema chileno y a la necesidad de ser competitivos en el mercado; (iii) compensatorias, que apuntan a la necesidad de resarcir perjuicios o injusticias que el sistema genera contra el contribuyente; $y$ (iv) afirmativas, que reivindican los cumplimientos tributarios creativos como opciones coherentes con el diseño del sistema y como estrategias productivas que redundarán en mayor crecimiento, inversión y creación de riqueza para el país (Atria 2019).

Gráfico 3. INFLUENCIA DE LAS PERCEPCIONES DE INJUSTICIA EN EL COMPORTAMIENTO TRIBUTARIO PROPIO

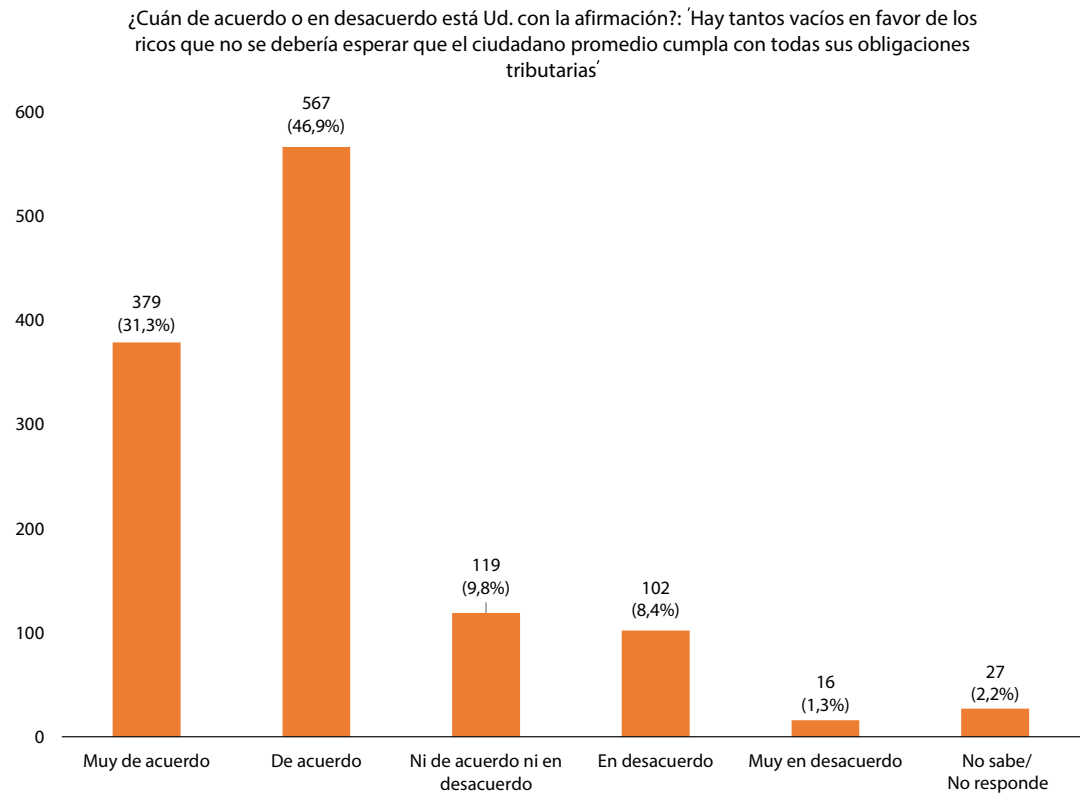

Fuente: Elaboración propia.

Tercero, y desde el lado ciudadano, es necesario incorporar en el análisis el efecto que han tenido en la ciudadanía los casos de tráficos de 
influencia, conflictos de interés y corrupción en Chile en la última década, los cuales han deteriorado la imagen de la administración tributaria y del respeto a la ley. Por ejemplo, la Encuesta Nacional sobre Cultura Tributaria en Chile 2021 permite visualizar que la percepción antes mencionada de que el sistema tributario beneficia a los más ricos puede afectar la disposición al pago de los ciudadanos, al punto de que, como muestra el Gráfico 3, 78,2\% se muestra 'de acuerdo' o 'muy de acuerdo' con que los vacíos en favor de los ricos justifican el no pago de impuestos.

\section{Conclusiones}

Este artículo ha indagado en las visiones sobre la tributación que ofrecen las aproximaciones de sociología económica y sociología fiscal. Las ciencias sociales y la sociología han desarrollado conceptos y explicaciones que permiten aportar a la comprensión de la economía, y con ella al comportamiento cotidiano de los actores, las transacciones económicas y los mercados. En este artículo se analiza esto con foco en las instituciones, el consentimiento y el cumplimiento tributario. En cada caso se discute cómo la sociología económica y fiscal ofrecen herramientas e interpretaciones que complementan o desafían aquellas elaboradas por las ciencias económicas, resaltando la incrustación de los impuestos en los aspectos sociales, culturales y políticos de la sociedad. Los impuestos operan en contextos específicos, están sometidos a coyunturas históricas críticas, son implementados de acuerdo con negociaciones cotidianas entre contribuyentes y fiscalizadores, pueden ser modificados a partir de la interacción entre la economía e intereses, valores y creencias, así como motivaciones muy diversas de los contribuyentes llevan a pagarlos, evadirlos o eludirlos. Asimismo, constituyen un instrumento no solo económico, sino también político, que otorga concreción a la noción de ciudadanía, y cuyo pago permite a los contribuyentes exigir mayor transparencia y rendición de cuentas al Estado.

Estas aproximaciones pueden aportar información relevante para entender el sistema tributario chileno en aspectos que consideran el grado de alineación entre sus objetivos y los que la ciudadanía le atribuye, su capacidad o incapacidad de reducir las grandes disparidades económicas, la legitimidad del Estado y del Servicio de Impuestos Internos (SII) para ejercer su función recaudadora y la inclusión política de los ciuda- 
danos como contribuyentes. Los impuestos tienen una presencia mucho más evidente en el debate público chileno y, por ende, la forma como las personas perciben los elementos anteriores puede no solo ayudar a explicar las mayores tasas de incumplimiento de los últimos años, sino también a proyectar nuevas condiciones que le otorguen sustento, justicia y efectividad al pacto fiscal del país.

Futuras investigaciones pueden aportar en la comprensión de estos y una variedad de fenómenos adicionales, como por ejemplo los contextos sociohistóricos en que se introdujo el impuesto a la renta en Chile, las coaliciones políticas y discursivas que han producido los resultados de las reformas tributarias de 1990 y 2014 —las más relevantes desde el retorno a la democracia- y las formas en que el SIl cumple su función fiscalizadora, lidiando al mismo tiempo con ciudadanos que demandan más formación tributaria y con contribuyentes que despliegan sofisticadas estrategias de planificación impositiva.

En las últimas décadas, la frontera entre sociología y economía se está redibujando, ofreciendo nuevas perspectivas en una variedad de problemas sociales, revitalizando una forma de cooperación que era más habitual en los orígenes de estas ciencias (Swedberg 1990, 5). En este sentido, es posible pensar una cercanía mayor entre el homo economicus y el homo sociologicus ( $\mathrm{Ng}$ y Tseng 2008), para lo cual el campo de la tributación ofrece un espacio lleno de posibilidades hacia el futuro. Esto no solo debería dar espacio a explicaciones más precisas sobre los impuestos, el Estado y el lazo fiscal, sino también, y sobre todo, a pactos fiscales e impuestos más justos que permitan enfrentar los enormes desafíos socioeconómicos que exhiben las sociedades contemporáneas.

\section{Bibliografía}

Abelin, M. 2012. Fiscal Sovereignty: Reconfigurations of Value and Citizenship in PostFinancial Crisis Argentina. Tesis PhD, Columbia University.

Agostini, C. 2013. Una reforma eficiente y equitativa del impuesto al ingreso en Chile (199-245). En Arellano, J. y Corbo, V. (eds.), Tributación para el desarrollo: estudios para la reforma del sistema chileno. Santiago: CEP, CIEPLAN.

Agostini, C. e Islas, G. 2018. Evolución del impuesto al ingreso en Chile (207-238). En Jaksić, I., Estefane, A. y Robles, C. (eds.), Historia política de Chile (1810-2010), tomo III. Santiago: Fondo de Cultura Económica.

Agostini, C., Engel, E., Repetto, A. y Vergara, D. 2018. Using Small Businesses for Individual Tax Planning: Evidence from Special Tax Regimes in Chile. International Tax and Public Finance 25, 1449-1489. 
Agostini, C., Martínez, C. y Flores, B. 2012. Distributional Effects of Eliminating the Differential Tax Treatment of Business and Personal Income in Chile. CEPAL Review 108, 175-201.

Allingham, M. y Sandmo, A. 1972. Income Tax Evasion: A Theoretical Analysis. Journal of Public Economics 1, 323-338.

Alm, J. y Torgler, B. 2011. Do Ethics Matter? Tax Compliance and Morality. Journal of Business Ethics 101(4), 635-651.

Aspers, P. 2001. Crossing the Boundary of Economics and Sociology: The Case of Vilfredo Pareto. American Journal of Economics and Sociology 60(2), 519-545.

Atkinson, A.B. 2015. Inequality. What can Be Done? Cambridge, London: Harvard University Press.

Atria, J. 2014. Tributación y desigualdad en Chile: características y perspectivas (115142). En Atria, J. (ed.), Tributación en sociedad: impuestos y redistribución en el Chile del siglo XXI. Santiago: RIL.

Atria, J. 2015. La relación entre desigualdad e impuestos como fuente de conflicto social: el caso de Chile (217-243). En Castillo, M. y Maldonado, C. (eds.), Desigualdades: tolerancia, legitimación y conflicto en las sociedades latinoamericanas. Santiago: RIL.

Atria, J. 2018. El resurgimiento de los impuestos en la sociedad chilena (279-309). En González, F. y Madariaga, A. (eds.), La constitución social, política y moral de la economía chilena. Santiago: RIL.

Atria, J. 2019. Legalism and Creativity: Tax Non-Compliance in the Eyes of the Economic Elite. International Review of Sociology 29(1), 58-79.

Atria, J., Castillo, J., Maldonado, L. y Ramírez, S. 2020. Economic Elites' Attitudes toward Meritocracy in Chile: A Moral Economy Perspective. American Behavioral Scientist 64(9), 1219-1241.

Atria, J., Groll, C. y Valdés, M. (eds.) 2018. Rethinking Taxation in Latin America: Reform and Challenges in Times of Uncertainty. Cham: Palgrave Macmillan.

Becker, G. 1968. Crime and Punishment: An Economic Approach. Journal of Political Economy 76, 169-217.

Beckert, J. 1996. What Is Sociological about Economic Sociology? Uncertainty and the Embeddedness of Economic Action. Theory and Society 25, 803-840.

Beckert, J. 2009. The Great Transformation of Embeddedness: Karl Polanyi and the New Economic Sociology (38-55). En Hann, C. (ed.), Market and Society: The Great Transformation Today. Cambridge: Cambridge University Press.

Bergman, M. 2009. Tax Evasion and the Rule of Law in Latin America: The Political Culture of Cheating and Compliance in Argentina and Chile. University Park, PE: Pennsylvania State University Press.

Biehl, A. y Labarca, J. 2018. Global Uncertainty in the Evolution of Latin American Income Taxes (89-122). En Atria, J., Groll, C. y Valdés, M. (eds.), Rethinking Taxation in Latin America: Reform and Challenges in Times of Uncertainty. Cham: Palgrave.

Biehl, A., Labarca, J. y Vela, J. 2019. Taxes without Taxpayers: The Invisibility of Taxes in Chile. Revista Mexicana de Ciencias Políticas y Sociales 64(236), 49-82.

Björklund Larsen, L. 2017. Shaping Taxpayers. Values in Action at the Swedish Tax Agency. New York, Oxford: Berghahn.

Blyth, M. 2002. Great Transformations: Economic Ideas and Institutional Change in the Twentieth Century. Cambridge: Cambridge University Press.

Bourdieu, P. 2005. Principles of an Economic Anthropology (75-89). En Smelser, N. y Swedberg, R. (eds.), The Handbook of Economic Sociology. Princeton, Oxford: Princeton University Press. 
Boylan, D. 1996. Taxation and Transition: The Politics of the 1990 Chilean Tax Reform. Latin American Research Review 31(1), 7-31.

Bräutigam, D. 2008. Taxation and State-building in Developing Countries (1-33). En Bräutigam, D., Fjeldstad, O. y Moore, M. (eds.), Taxation and State-building in Developing Countries: Capacity and Consent. Cambridge: Cambridge University Press.

Campbell, A.L. 2011. Policy Feedbacks and the Impact of Policy Designs on Public Opinion. Journal of Health Politics, Policy and Law 36(6), 961-973.

Campbell, J. 1993. The State and Fiscal Sociology. Annual Review of Sociology 19, 163185.

Castelletti, B. 2013. How Redistributive is Fiscal Policy in Latin America?: The Case of Chile and Mexico. OECD Development Centre Working Papers 318.

Castillo, J. y Olivos, F. 2014. Redistribución e impuestos: un análisis desde la opinión pública (143-166). En Atria, J. (ed.), Tributación en sociedad: impuestos y redistribución en el Chile del siglo XXI. Santiago: Uqbar.

Cummings, R., Martinez-Vazquez, J., McKee, M. y Torgler, B. 2009. Tax Morale Affects Tax Compliance: Evidence from Surveys and an Artefactual Field Experiment. Journal of Economic Behavior \& Organization 70, 447-457.

Currie, T., Turchin, P., Bednar, J., Richerson, P., Schwesinger, G., Steinmo, S., Wacziarg, R. y Wallis, J. 2016. Evolution of Institutions and Organizations (199-234). En Wilson, D. y Kirman, A. (eds.), Complexity and Evolution: Towards a New Synthesis for Economics. Cambridge, MA:The MIT Press.

Cheyre, H. 1986. Análisis de las reformas tributarias en la década 1974-1983. Estudios Públicos 21. Disponible en: https://www.estudiospublicos.cl/index.php/cep/ article/view/1697/2885 [3 de noviembre 2021].

DiMaggio, P. 1988. Interest and Agency in Institutional Theory. En Zucker, L. (ed.), Institutional Patterns and Culture. Cambridge, MA: Balling.

Dobbin, F. 2005. Comparative and Historical Approaches to Economic Sociology (2648). En Smelser, N. y Swedberg, R. (eds.), The Handbook of Economic Sociology. Princeton, Oxford: Princeton University Press.

Engel, E., Galetovic, A. y Raddatz, C. 1999. Taxes and Income Distribution in Chile: Some Unpleasant Redistributive Arithmetic. Journal of Development Economics 59(1), 155-192.

Fairfield, T. 2015. Private Wealth and Public Revenue in Latin America. Cambridge: Cambridge University Press.

Fairfield, T. y Jorratt, M. 2016. Top Income Shares, Business Profits, and Effective Tax Rates in Contemporary Chile. Review of Income and Wealth 62(S1), S120-S144.

Fligstein, N. 1996. Markets as Politics: A Political-Cultural Approach to Market Institutions. American Sociological Review 61(4), 656-673.

Frey, B. y Holler, M. 1998. Tax Compliance Policy Reconsidered. Homo Oeconomicus 15, 27-45.

Garud, R., Hardy, C. y Maguire, S. 2007. Institutional Entrepreneurship as Embedded Agency: An Introduction to the Special Issue. Organization Studies 28(7), 957969.

Gil, M. y Atria, J. 2021. Fiscal Aftershocks: Taxes and Catastrophes in Chilean History. Revista de Historia Económica / Journal of Iberian and Latin American Economic History, 1-39. DOI:10.1017/S0212610921000070.

Goldscheid, R. 1917. Staatssozialismus oder Staatskapitalismus: ein finanzsoziologischer Beitrag zür Lösung des Staatsschulden-Problems. Wien, Leipzig: Anzengruber Verlag. 
Graetz, M. y Wilde, L. 1985. The Economics of Tax Compliance: Fact and Fantasy. National Tax Journal 38(3), 355-363.

Granovetter, M. 1985. Economic Action and Social Structure: The Problem of Embeddedness. American Journal of Sociology 91(3), 481-510.

Grimson, A. y Roig, A. 2011. Las percepciones sociales de los impuestos (87-122). En Nun, J. (comp.), La desigualdad y los impuestos II: materiales para la discusión. Buenos Aires: Capital Intelectual.

Ide, E. y Steinmo, S. 2009. The End of the Strong State? On the Evolution of Japanese Tax Policy (119-137). En Martin, I.W., Mehrotra, A.K. y Prasad, M. (eds.), The New Fiscal Sociology: Taxation in Comparative and Historical Perspective. Cambridge: Cambridge University Press.

Jorratt, M. 2009. La tributación directa en Chile: equidad y desafíos. CEPAL Serie Macroeconomía del Desarrollo № 92.

Jorratt, M. 2013. Gastos tributarios y evasión tributaria en Chile: evaluación y propuestas (39-142). En Arellano, J. y Corbo, V. (eds.), Tributación para el desarrollo: estudios para la reforma del sistema chileno. Santiago: CEP, CIEPLAN.

Kato, J. y Toyofuku, M. 2018. The Divergent Paths of Tax Development during Different Waves of Democratization. Japanese Journal of Political Science 19(3), 333-352.

Kirchler, E., Maciejovsky, B. y Schneider, F. 2003. Everyday Representations of Tax Avoidance, Tax Evasion, and Tax Flight: Do Legal Differences Matter? Journal of Economic Psychology 24, 535-553.

Kogler, C., Batrancea, L., Nichita, A., Pantya, J., Belianin, A. y Kirchler, E. 2013. Trust and Power as Determinants of Tax Compliance: Testing the Assumptions of the Slippery Slope Framework in Austria, Hungary, Romania and Russia. Journal of Economic Psychology 34, 169-180.

Levi, M. 1988. Of Rule and Revenue. Berkeley: University of California Press.

Lieberman, E. 2001. National Political Community and the Politics of Income Taxation in Brazil and South Africa in the Twentieth Century. Politics \& Society 29(4), 515555.

Lieberman, E. 2009. The Politics of Demanding Sacrifice: Applying Insights from Fiscal Sociology to the Study of AIDS Policy and State Capacity (101-118). En Martin, I.W., Mehrotra, A.K. y Prasad, M. (eds.), The New Fiscal Sociology: Taxation in Comparative and Historical Perspective. Cambridge: Cambridge University Press.

Lipsky, M. 2010. Street-level Bureaucracy. Dilemmas of the Individual in Public Services. New York: Russell Sage Foundation.

López, R. y Figueroa, E. 2011. Fiscal Policy in Chile: Hindering Sustainable Development by Favoring Myopic Growth. Serie de Documentos de Trabajo 346, Universidad de Chile.

Mann, M. 1984. The Autonomous Power of the State: Its Origins, Mechanisms and Results. European Journal of Sociology 25(2), 185-213.

Martin, I.W., Mehrotra, A.K. y Prasad, M. 2009. The Thunder of History: The Origins and Development of the New Fiscal Sociology (1-27). En Martin, I.W., Mehrotra, A.K. y Prasad, M. (eds.), The New Fiscal Sociology: Taxation in Comparative and Historical Perspective. Cambridge: Cambridge University Press.

McBarnet, D. 2001. When Compliance is not the Solution but the Problem: From Changes in Law to Changes in Attitude. Centre for Tax System Integrity Working Paper 18.

Moore, M. 2008. Between Coercion and Contract: Competing Narratives on Taxation and Governance. En Bräutigam, D., Fjeldstad, O. y Moore, M. (eds.), Capacity 
and Consent: Taxation and State Building in Developing Countries. Cambridge: Cambridge University Press.

Murphy, R 2016. The Joy of Tax. How a Fair Tax System Can Create a Better Society. London: Corgi.

Murphy, L. y Nagel, T. 2002. The Myth of Ownership: Taxes and Justice. Oxford: Oxford University Press.

Napoli, E. y Navia, P. 2012. La segunda es la vencida. El caso del royalty de 2004 y del impuesto específico a la gran minería de 2005 en Chile. Gestión y Política Pública XXI(1), 141-183.

Nee, V. 2005. The New Institutionalisms in Economics and Sociology (49-74). En Smelser, N. y Swedberg, R. (eds.), The Handbook of Economic Sociology. Princeton and Oxford: Princeton University Press.

Ng, I. y Tseng, L.-M. 2008. Learning to Be Sociable. The Evolution of Homo Economicus. The American Journal of Economics and Sociology 67(2), 265-286.

North, D. 1991. Institutions. Journal of Economic Perspectives 5(1), 197-112.

Palma, G. y Marcel, M. 1990. Kaldor y el discreto encanto de la burguesía chilena. Colección Estudios Cieplan 28, 85-120.

Piketty, T. 2017. Toward a Reconciliation between Economics and the Social Sciences (543-566). En Boushey, H., DeLong, J.B. y Steinbaum, M. (eds.), After Piketty: The Agenda for Economics and Inequality. Cambridge: Harvard University Press.

Polanyi, K. 1992 [1957]. La gran transformación: los orígenes políticos y económicos de nuestro tiempo. México DF: Fondo de Cultura Económica.

Portes, A. 2010. Economic Sociology: A Systematic Inquiry. Princeton: Princeton University Press.

Rosanvallon, P. 2012. La sociedad de los iguales. Barcelona: RBA.

Sá, C., Martins, A. y Gomes, C. 2014. Tax Morale, Occupation and Income Level: An Analysis of Portuguese Taxpayers. Journal of Economics, Business and Management 2(2), 112-116.

Sahm, R. 2019. Theorie und Ideengeschichte der Steuergerechtigkeit: Eine steuertheoretische, steuerrechtliche und politische Betrachtung. Berlin: Springer Gabler.

Scheve, K. y Stasavage, D. 2016. Taxing the Rich. A History of Fiscal Fairness in the United States and Europe. Princeton, NJ: Princeton University Press.

Schultz, U. (Hrsg.) 1992. Mit den Zehnten fing es an: eine Kulturgeschichte der Steuer. München: C.H. Beck.

Schumpeter, J. 2000. La crisis del estado fiscal. Revista Española de Control Externo 2(5), 147-192.

Shiller, R. 2019. Narrative Economics. How Stories Go Viral \& Drive Major Economic Events. Princeton, Oxford: Princeton University Press.

Skocpol, T. y Amenta, E. 1986. States and Social Policies. Annual Review of Sociology 12, 131-157.

Sloterdijk, P. 2010. Die nehmende Hand und die gebende Seite. Berlin: Suhrkamp.

Smelser, N. y Swedberg, R. 2005. Introducing Economic Sociology (3-25). En Smelser, N. y Swedberg, R. (eds.), The Handbook of Economic Sociology. Princeton, Oxford: Princeton University Press.

Steinmo, S. 1993. Taxation and Democracy: Swedish, British and American Approaches to Financing the Modern State. New Haven, CT: Yale University Press.

Steinmo, S. 2003. The Evolution of Policy Ideas: Tax Policy in the 20th Century. British Journal of Politics and International Relations 5(2), 206-236. 
Steinmo, S. 2018. Introduction. The Leap of Faith (3-32). En Steinmo, S. (ed.), The Leap of Faith. The Fiscal Foundations of Successful Government in Europe and America. Oxford: Oxford University Press.

Swedberg, R. 1990. Economics and Sociology. Redefining their Boundaries: Conversations with Economists and Sociologists. Princeton, NJ: Princeton University Press.

Swedberg, R. y Granovetter, M. 1992. Introduction (1-26). En Granovetter, M. y Swedberg, R. (eds.), The Sociology of Economic Life. Boulder, CO: Westview Press.

Taylor, N. 2003. Understanding Taxpayer Attitudes through Understanding Taxpayer Identities. En Braithwaite, V. (ed.), Taxing Democracy: Understanding Tax Avoidance and Evasion. Aldershot: Ashgate.

Tilly, C. (ed.) 1975. The Formation of National States in Western Europe. Princeton: Princeton University Press.

Weber, M. 2008 [1922]. Economía y sociedad. México DF: Fondo de Cultura Económica.

Williamson, V. 2017. Read My Lips: Why Americans Are Proud to Pay Taxes. Princeton: Princeton University Press.

Wormald, G. y Cárdenas, A. 2014. Formación y desarrollo del Servicio de Impuestos Internos en Chile: un análisis institucional (81-114). En Atria, J. (ed.), Tributación en sociedad: impuestos y redistribución en el Chile del siglo XXI. Santiago: Uqbar.

Wynter, C. y Oats, L. 2021. Knock, Knock: The Taxman's at Your Door! Practice Sense, Empathy Games, and Dilemmas in Tax Enforcement. Journal of Business Ethics 169, 279-292.

Zelizer, V. 2010. Economic Lives. How Culture Shapes the Economy. Princeton: Princeton University Press. EP 